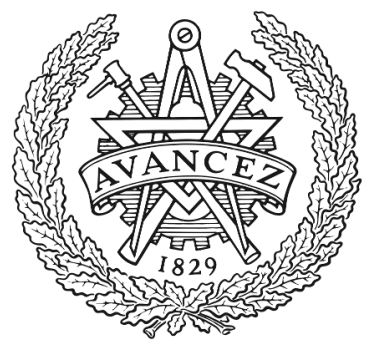

CHALMERS

UNIVERSITY OF TECHNOLOGY

\title{
Investigation of Wheel Ventilation-Drag using a Modular Wheel Design Concept
}

Downloaded from: https://research.chalmers.se, 2023-04-26 01:49 UTC

Citation for the original published paper (version of record):

Vdovin, A., Bonitz, S., Landström, C. et al (2013). Investigation of Wheel Ventilation-Drag using a Modular Wheel Design Concept. SAE International Journal of Passenger Cars - Mechanical Systems, 6(1): 308-315. http://dx.doi.org/10.4271/2013-01-0953

N.B. When citing this work, cite the original published paper. 
This is a preprint version of the following paper:

Vdovin, A., Bonitz, S., Landstrom, C., and Lofdahl, L., "Investigation of Wheel Ventilation-Drag using a Modular Wheel Design Concept," SAE Int. J. Passeng. Cars - Mech. Syst. 6(1):308-315, 2013, https://doi.org/10.4271/2013-01-0953.

Being a preprint and not the final accepted manuscript, this version does not include the corrections made to the paper after the review process and therefore it is slightly different from the published journal article. The readers are advised to follow the DOI link to access the published version online.

(c) 2019. This manuscript version is made available under the CC-BY-NC-ND 4.0 license http://creativecommons.org/licenses/by-nc-nd/4.0/

Type Paper Number Here

Investigation of wheel ventilation-drag using a modular wheel design concept

\author{
Author, co-author (Do NOT enter this information. It will be pulled from participant tab \\ in MyTechZone) \\ Affiliation (Do NOT enter this information. It will be pulled from participant tab in MyTechZone)
}

Copyright (C) 2013 SAE International

\section{ABSTRACT}

Passenger car fuel consumption is a constant concern for automotive companies and the contribution to fuel consumption from aerodynamics is well recognized. Several studies have been published previously on the aerodynamics of wheels. One area of wheel aerodynamics discussed in some of these earlier works is the so called ventilation resistance.

This study investigates ventilation resistance on a number of 17 inch rims in the Volvo Cars Aerodynamic Wind Tunnel. The ventilation resistance was measured using a custom build suspension and the tractive force measurement system installed in the Wheel Drive Units (WDUs). The study aims at identifying wheel design factors that have significant effect on the ventilation resistance for the investigated wheel size.

The results show that it was possible to measure similar power requirements to rotate the wheels as was found in previous works. The magnitude of the measured ventilation resistance confirms the conclusion that this effect should be taken into account when designing a wheel.

It was found that some of the rim design factors have greater influences on the ventilation resistance than others. It was also shown that one of the investigated rims had lower ventilation resistance than measured for the fully-covered wheel configuration.

\section{INTRODUCTION}

With constantly growing fuel prices and toughening of environmental legislation, vehicle industry in struggling to reduce fuel consumption and decrease emission levels for the new and existing vehicles. One of the ways to achieve this goal is to improve aerodynamic performance by decreasing aerodynamic resistance. There are different areas of the vehicle that are known to be of great importance for the aerodynamic drag, one of them that is going to be discussed in this paper is the area of wheelhouses. Rotating wheels together with the wheelhouses can produce up to $35 \%$ of total aerodynamic drag [1], [2]. Furthermore, there are power losses associated with resistance moment acting on the wheels and originating from the relative movement of the wheels in the air. In order to better understand those losses a closer look at forces acting on the rotating wheel is required.

In Figure 1 moments acting on the rotating wheel around the rotation axis and forces resulting in such movements can be found. $\mathrm{T}$ is the torque applied from the gearbox through the

Page 1 of 9 
driveshaft; it is counteracted by a number of moments and forces.

$$
M_{\text {inertia }}+M_{b e}+M_{b r}+M_{d s}+M_{s}+M_{\text {vent }}
$$

Figure 1. Moments acting in the direction of wheel rotation and forces resulting in such moments

Firstly, there is a resistance moment $N \cdot e$ produced due to uneven distribution of load in the contact patch of the tyre. Secondly, different resistance moments exist due to inertia of the wheel, shaft and gearbox $M_{\text {inertia }}$, due to frictional losses in bearings $M_{b e}$ and brakes $M_{b r}$. Thirdly, one can identify resistance moment $M_{S}$ occurring due to relative slip between the tire and ground surface in the contact patch. Fourthly, there is a moment produced by tractive force $F_{\text {trac }}$ acting in the contact patch, this force also includes rolling resistance force. The last moment $M_{\text {vent }}$ is called ventilation moment and it occurs due to the wheel rotation in the airflow.

This resistance moment was previously investigated both experimentally [2], [3] and using CFD simulations [4]. In this paper ventilation resistance is considered to be a result of three effects acting simultaneously:

- the uneven normal pressure distribution around the tire

- the surface friction between the air and the wheel

- the fan-blade effect, which produces air rotation and creates pressure differences on the wheel rim blades

If considering aerodynamic resistance of a vehicle in general, one should take into account both aerodynamic drag force and ventilation resistance [3].This can be achieved by expressing ventilation resistance in terms of drag coefficient $C_{D}$ and combining aerodynamic $C_{D(A D)}$ with ventilation $C_{D(v e n t)}$. Ventilation resistance coefficient in this case can be defined similarly to aerodynamic drag coefficient:

$$
C_{D(\text { vent })}=\frac{F_{\text {trac }}^{\prime}}{\frac{1}{2} \rho V_{\infty}^{2} A}
$$

where $F_{\text {trac }}^{\prime}$ is a part of traction force that corresponds to ventilation resistance, $\rho$ is air density, $V_{\infty}$ is a free stream velocity and $A$ is a reference area.

\section{EXPERIMENTAL SETUP}

The measurement of ventilation resistance cannot be done on isolated wheel as ventilation resistance is affected by the airflow inside the wheelhouse; therefore a full vehicle test is required.

All measurements were conducted in the Volvo Car Corporation full scale aerodynamic wind tunnel using a Volvo S60 standard production car as a test vehicle. The test section of the wind tunnel has a cross sectional area of $27 \mathrm{~m}^{2}$ with slotted wall inserts. An overview of the tunnel and its different systems can be found in Figure 2.

The tunnel is equipped with a five belt moving ground system, installed on a turntable. The system consists of a center belt running in-between the wheels and four Wheel Drive Units (WDUs) rotating the wheels, see

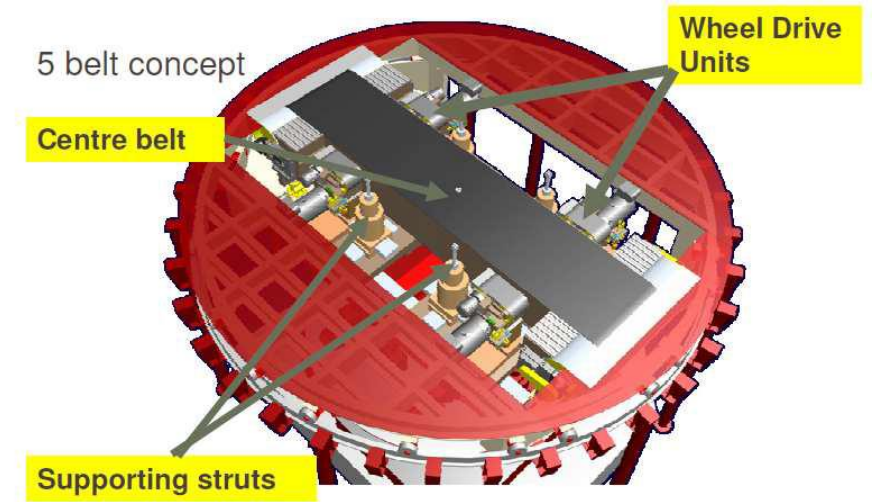

Figure 3. The WDUs are also connected to the wind tunnel balance below the turntable. The measurement balance is used to obtain forces and moments acting on the vehicle.

The vehicle is restrained in position and supported by four struts that are also connected to the balance and that allow to change the vehicle ride height during the experiment and lift it up if needed. Figure 4 shows the lifted test vehicle held by the struts. In order ensure realistic boundary conditions five belt system also includes distributed suction zones and tangential blowing as can be seen in Figure 2. 


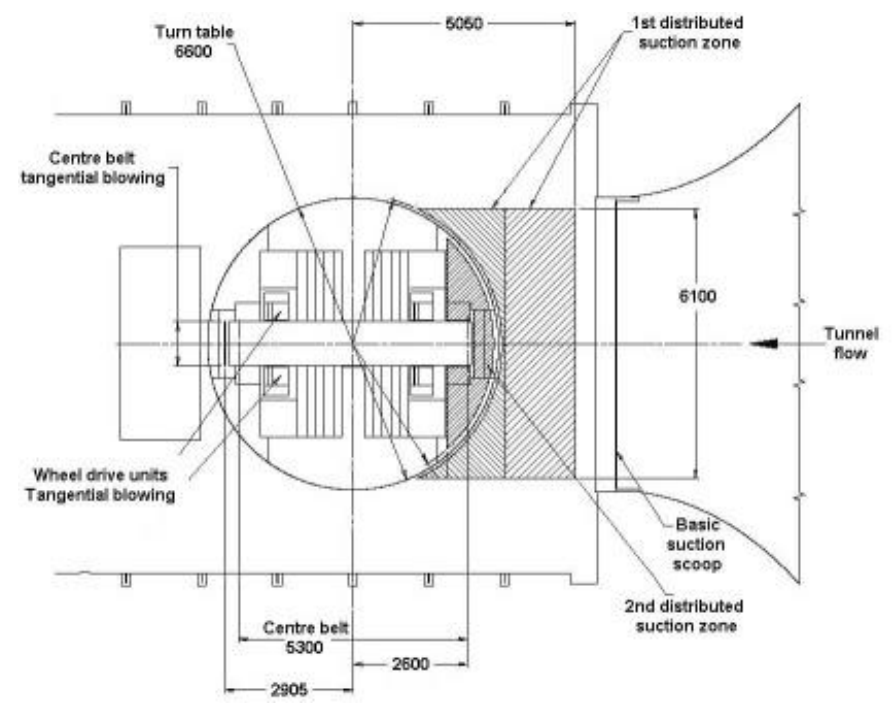

Figure 2. Overview of Volvo wind tunnel section [5]

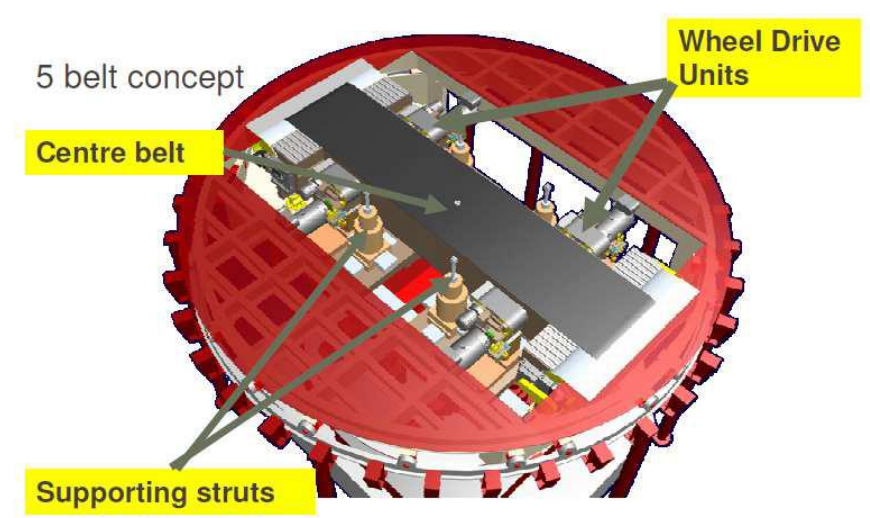

Figure 3. Five belt moving ground system [5]

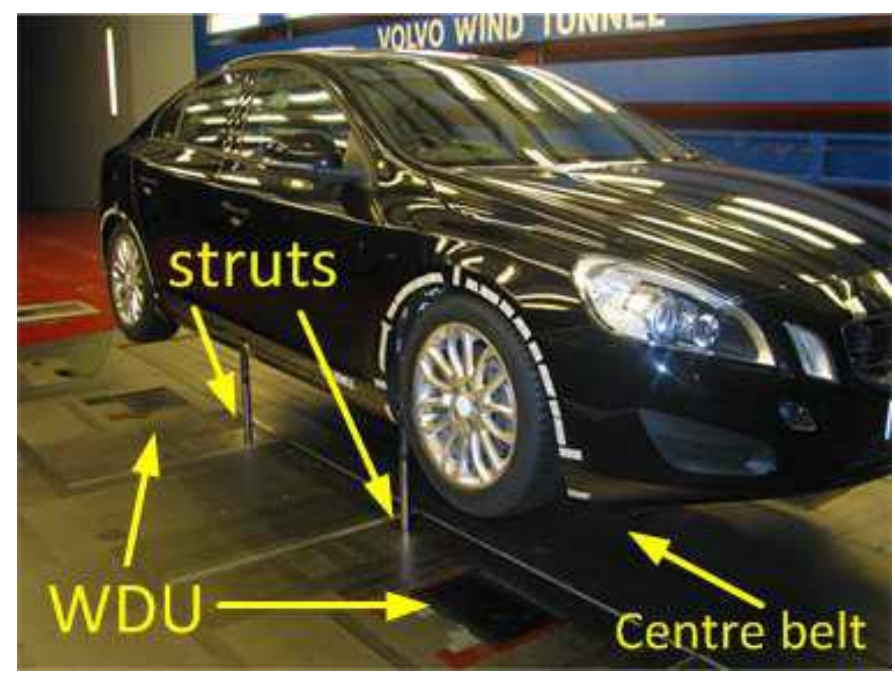

Figure 4. Test vehicle lifted using struts
As described earlier four vehicle struts and four WDUs are both standing on the balance frame. That makes any force between the vehicle tire and WDU to be an internal force; therefore it is not measured by the balance. The reason for having this set-up is that it makes rolling resistance an internal force as well, meaning that aerodynamic drag force can be measured directly without compensating for rolling resistance. In order to assess ventilation resistance the moment required to rotate the wheel at operational velocity needs to be calculated. Hence, traction force, i.e. longitudinal component of the force acting in the contact patch, has to be measured. For that purpose WDUs are equipped with load cells that allow measuring the tractive force. Knowing the tractive force, the power requirement to rotate the wheel is easily computed.

\section{MINIMIZING VARIOUS LOSSES}

In order to separate the amount of power needed to overcome ventilation resistance from the power losses due to other resistances, all other sources of losses and resistances acting on the wheel have to be either eliminated or measured.

Minimizing rolling resistance is achieved by using a special suspension setup. The shock absorbers are removed and replaced with restrain posts, see Figure 5. This makes it possible to control the position of the wheel inside wheelhouse with the aid of a threaded rod. In this case the weight of the vehicle is almost completely supported by the struts of the wind tunnel and therefore rolling resistance is minimized.

As the wheels are driven by the WDUs and not by the engine, the contact between the wheels and WDUs must be maintained, hence there is always some residual rolling resistance.

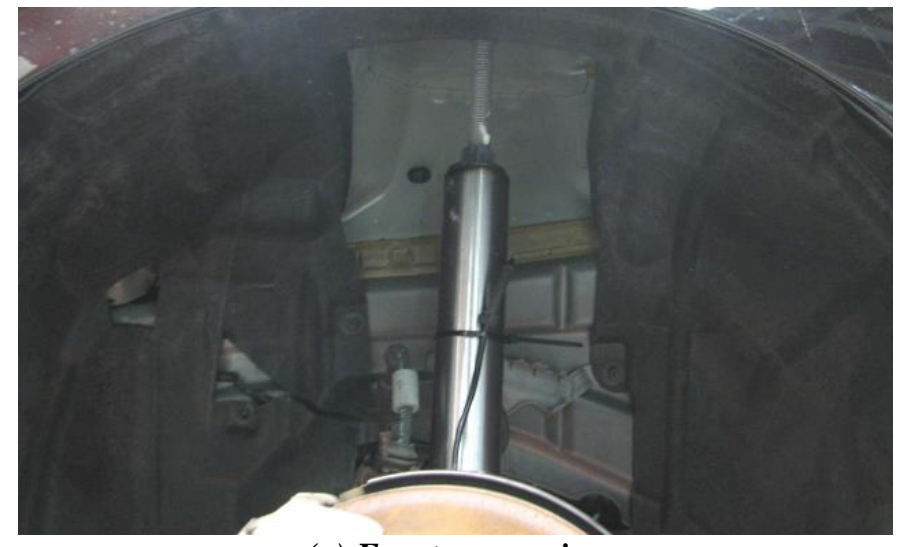

(a) Front suspension 


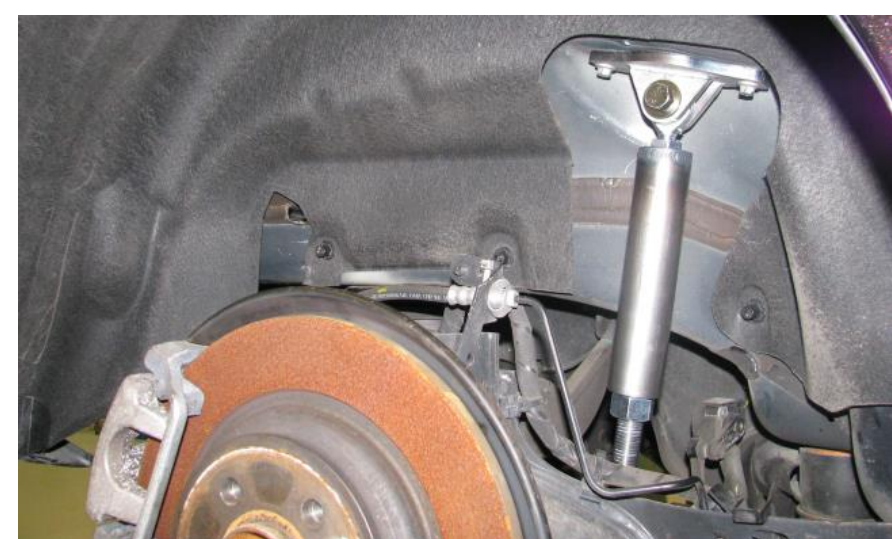

(b) Rear suspension

Figure 5. Modified suspension at front and rear

When preparing for the test the vehicle is placed on the struts and the ride height is set, then the wheels are lifted up inside wheelhouses using the modified suspension setup in order to get only a slight contact. To ensure same vertical load on each wheel a simple weight scale is used. The suspension is adjusted to have a load of $4 \mathrm{~kg}$ per each wheel. The rolling resistance coefficient $f_{r r}$ of 0.008 is assumed; therefore a residual rolling resistance force can be calculated using following equation:

$$
F_{r r}=f_{r r} N
$$

Substituting the numbers one will get a value of $0.314 \mathrm{~N}$ for one wheel or $1.256 \mathrm{~N}$ for all four wheels.

As it has been previously investigated when the wheel starts to rotate there is an expansion in the tire due to inertia [6]. This expansion changes the tire shape, see Figure 6, and affects the rolling resistance. The tire radius may change by as much as $8 \mathrm{~mm}$, depending on the material properties, weight of the vehicle and speed. For the set-up used during the test the maximum tire expansion measured was $2.5 \mathrm{~mm}$ for the velocity of $200 \mathrm{~km} / \mathrm{hour}$.
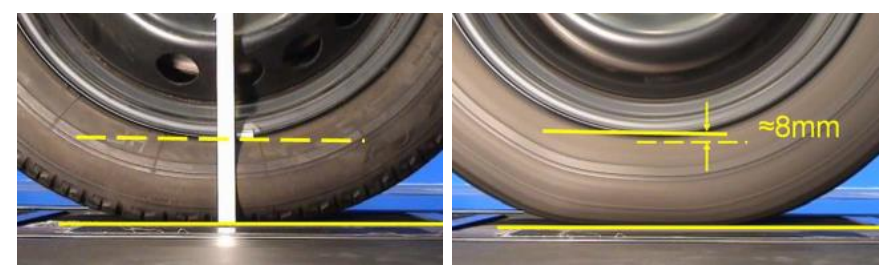

Figure 6. Tire expansion in radial direction

In order to counteract this change and maintain the rolling resistance as low as possible during the experiment the vehicle ground clearance is being changed. With the increasing speed the vehicle is lifted by means of changing the height of the vehicle struts.

Considering other losses, the drive shafts were removed and brake pads were dismounted to ensure no frictional losses due to these components. With no connection between wheels and the gearbox all transmission losses are removed. Frictional moment in the bearings was estimated using dynamometric screwdriver. It is known that frictional moment in bearings is changing with speed but for the certain test conditions it can be assumed to have a constant value [7]. During the test a measured value of $0.7 \mathrm{Nm}$ was used as a constant frictional moment in bearings.

The load cells measuring tractive force have an uncertainty of $\pm 2 \mathrm{~N}$. That means that when calculating power the measurement uncertainty grows with the speed. In Figure 7 a graph is given showing power needed to rotate all four wheels in the air for one of the configurations; the measurement uncertainty is represented by error bars.

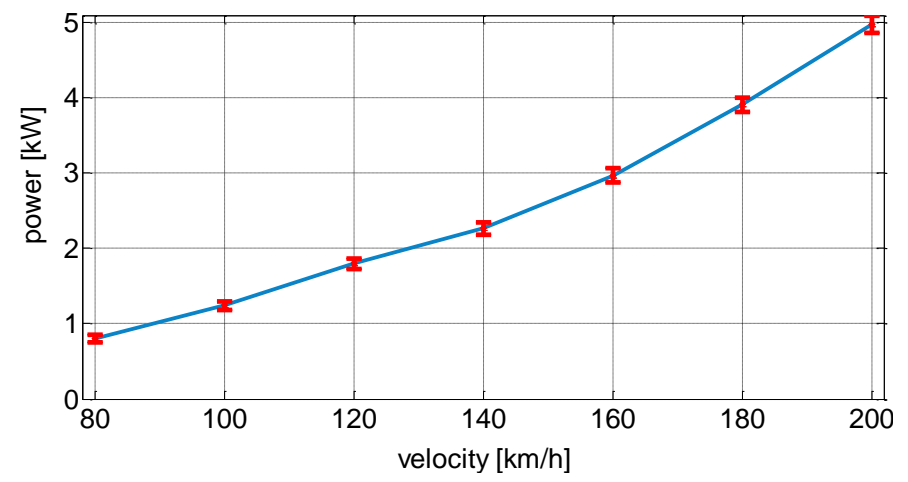

Figure 7. Measurement uncertainty for power represented by error bars

For the aerodynamic drag force measurements the balance has an uncertainty of $\pm 5 \mathrm{~N}$, but as the drag force values are much higher than values for the tractive force, measurement precision for the balance is actually better.

When comparing values for ventilation resistance obtained during the test and the ones from the literature [3], one can say that they have close values and show similar trend. Moreover, the differences for corresponding configurations are within the uncertainty interval of the measurements.

\section{CONFIGURATIONS}

In order to test different rim designs a set of previously developed modular wheels is used [8]. Each wheel has a five spoke aluminum rim with a set of several add-on parts manufactured using selective laser sintering (SLS) rapid prototyping, see Figure 8. This allows fast changing of rim configuration without dismounting or changing the wheel, thereby ensuring same wheel and tire properties and same deformations during the test.

All of the four wheels were of the same width and equipped with the same type of tires. Tire pressure for all for wheels was maintained equal during the experiment. 


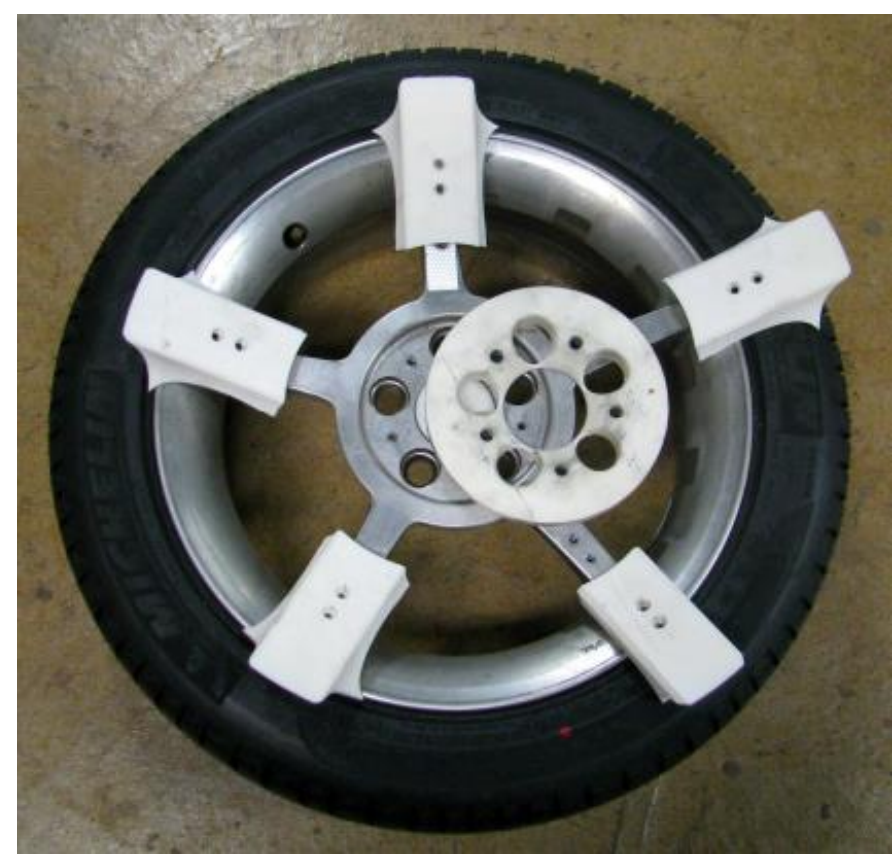

Figure 8. Modular wheel system

Unfortunately using modular wheel limits the experiment to 17 inch wheels only, as it was the only size available. A total of 14 wheel rim designs were investigated. They are presented in Figure 9. As it can be seen all of the designs tested have five spokes, due to the geometry of the row rim. The only obvious exception is a fully covered wheel, Figure 9(b). Other designs differ is in shape and size of the spokes and in the area coverage from the inner and outer radii. There are also two rims with three-dimensional blade spokes, see Figure $9(\mathrm{~g}, \mathrm{~h})$, one designed to facilitate the airflow out from the wheelhouse and another one pumping the air into it. Lastly, a high drag profile configuration, see Figure $9(\mathrm{k})$, is introduced in order to have a reference point to be able to compare different designs.

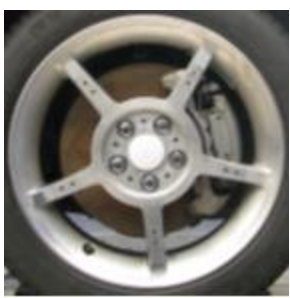

(a) Row rim

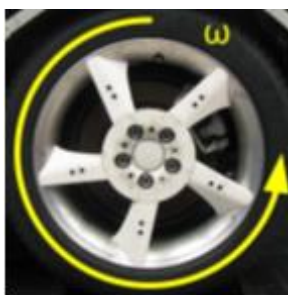

(d) Fan blade IN

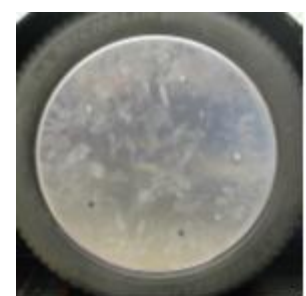

(b) Fully closed rim

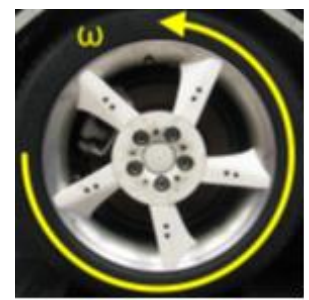

(e) Fan blade OUT

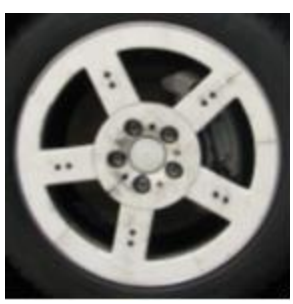

(c) Slim outer radius

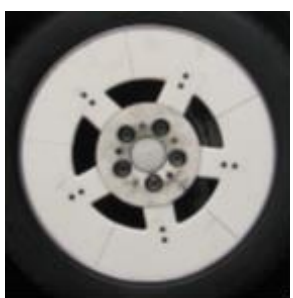

(f) Thick outer radius

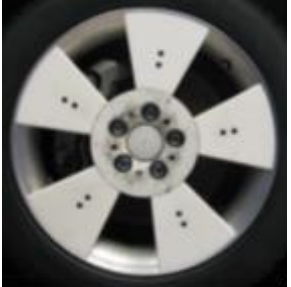

(g) Thick sun blades

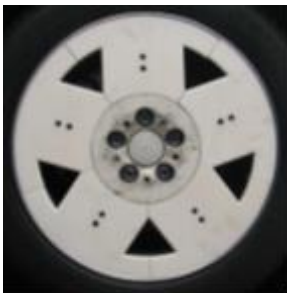
(outer radius) (j) Thick spokes

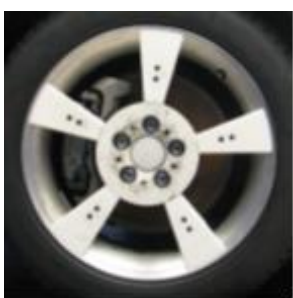

(h) Slim sun blades

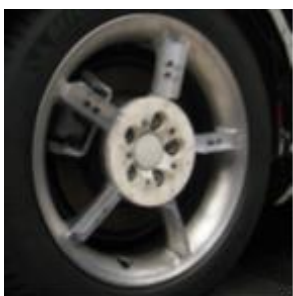

(k) High drag profile(ref)

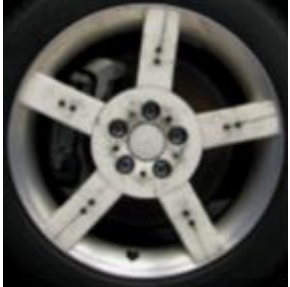

(i) Base spokes

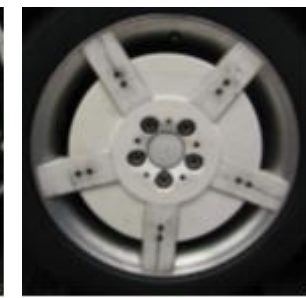

(l) Star cover

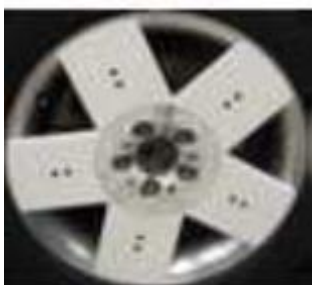

(m) Thick base spokes

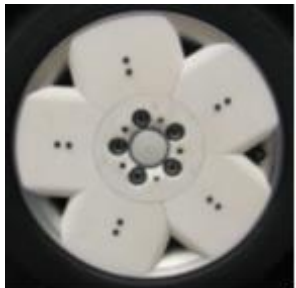

(n) Flower cover
Figure 9. Rim designs

\section{RESULTS}

The designs presented above were tested; power requirement to overcome ventilation resistance was measured and expressed in terms of aerodynamic coefficient $C_{D}$. As it was expected high drag profile show the highest measured ventilation resistance and the highest aerodynamic drag force, therefore this rim design was used as a reference when comparing all other designs. In Figure 10 percentage difference in ventilation resistance for different rim designs in comparison to reference design can be observed.

Most of the curves are rather close to each other but some conclusions can still be made. It can be seen that thick outer radius cover has the lowest ventilation resistance for speeds above and equal to $100 \mathrm{~km} /$ hour. One of the reasons for that may be in the fact that the openings for this cover are located closer to the center of the wheel thereby exposed spokes has lower relative velocity hence they have lower pressure on the leading edge of the spoke than for other rim designs. Another reason may be in the fact that by introducing cover at the outer radius the gap between the rim and the brake disk is being shielded, see Figure 11, thereby considerably reducing the airflow through the wheel.

Page 5 of 9 


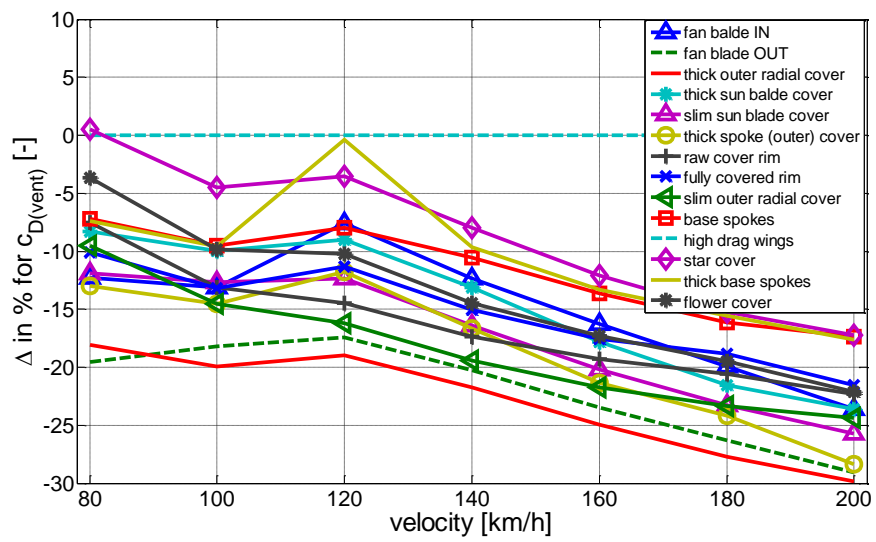

Figure 10. Percentage difference in ventilation resistance for different configurations
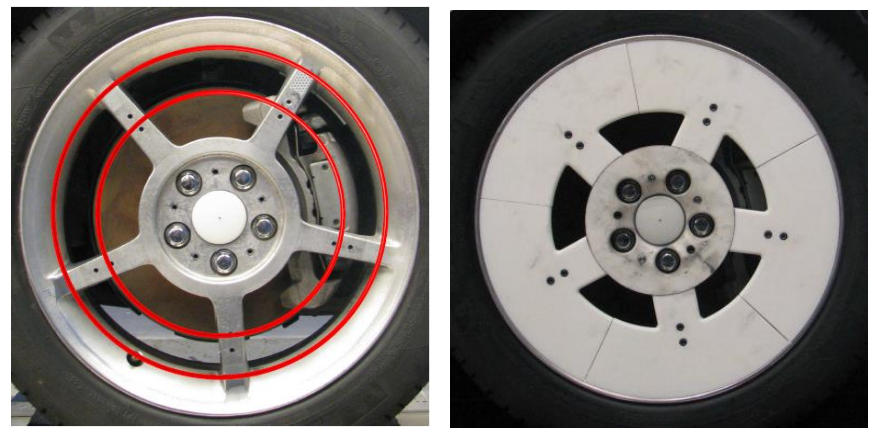

Figure 11. A gap between the rim and the brake disk, open and shielded by the outer radius cover

These ideas are supported by the fact that all rim designs with outer radius covered [thick outer radius, thick spoke (outer radius), slim outer radius] have generally performed significantly better than other designs. The second best configuration is fan blade out one. The spokes of this configuration are designed to pump the air out of the wheelhouse thereby reducing pressure inside. Moreover, the aerodynamic shape of the blades for this configuration with smoother corners allows having smaller stagnation regions on the rim leading edge.

If comparing worst designs from ventilation resistance point of view, star cover should be mentioned as it has the second worst result after high drag profile rims. Base spokes and thick base spokes have rather high ventilation resistance as well.

Fully closed rim design deserves special attention; it is expected to result in the lowest aerodynamic drag force [8] but when comparing ventilation resistances, it shows intermediate performance. This can be explained by the fact that this type of cover completely blocks the air through the wheel rim and thereby more attached flow can be achieved on the outer side of the wheel, hence increasing surface friction. Also the pressure on the inner side of the wheel may be higher due to the closed design.

Figure 12 shows the percentage difference between different designs in terms of aerodynamic drag, high drag profile rim is used as a reference case.

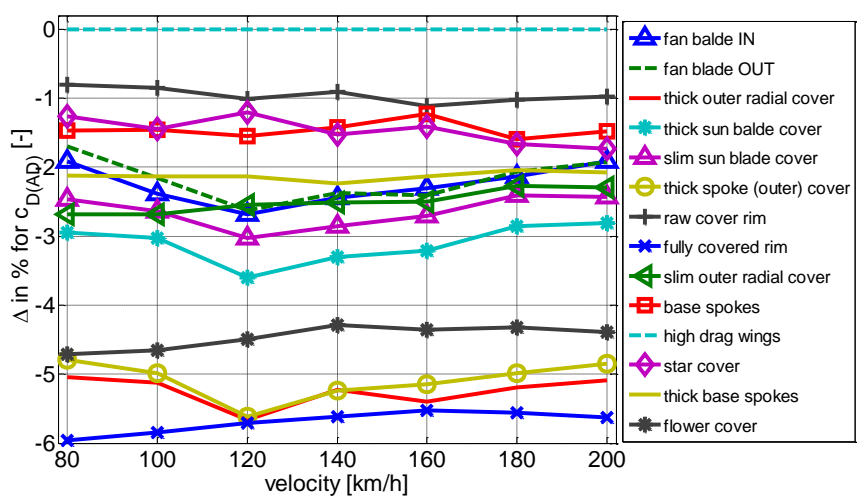

\section{Figure 12. Percentage difference in aerodynamic drag for different configurations}

First thing that can be seen is that changing rim design has lower influence on aerodynamic drag force than on the ventilation resistance, $6 \%$ at maximum compared to $30 \%$ in case of ventilation resistance. That is understandable since the aerodynamic drag force is measured for the entire vehicle and not for the wheels.

As it was expected, fully covered rim design has the lowest aerodynamic drag, as it allows having a more attached flow. Second best design is thick outer radial cover with a rather similar but slightly worse performance. The importance of having an outer radius of the rim covered for lower aerodynamic drag force was already known as it has been investigated before [9], [10]. It is also supported by the fact that rim design with thick spokes and outer radius covered is the third best closely followed by the flower cover rim which is similar to completely covered wheel in terms of the large area being masked.

The use of fan blade out design, that showed to be good in terms of ventilation resistance, leads to a much higher aerodynamic drag value in comparison to four best designs.

Considering the worst designs it is obvious that large open areas with blunt spokes shapes, without outer radius covered result in the largest aerodynamic drag.

As both $\mathrm{C}_{\mathrm{D}(\text { vent })}$ and $\mathrm{C}_{\mathrm{D}(\mathrm{AD})}$ are dimensionless it is possible to add them up in order to get a total aerodynamic resistance coefficient $C_{D(A D+v e n t)}$. This coefficient, normalized by the values for high drag profile is presented in Figure 13. As expected fully covered wheel shows good results, but as it can be seen thick outer radial cover actually performs better throughout all velocity range. The reason for that is low 
ventilation resistance of this design. It is also better from the brakes cooling point of view, as it allows air exchange through the rim.

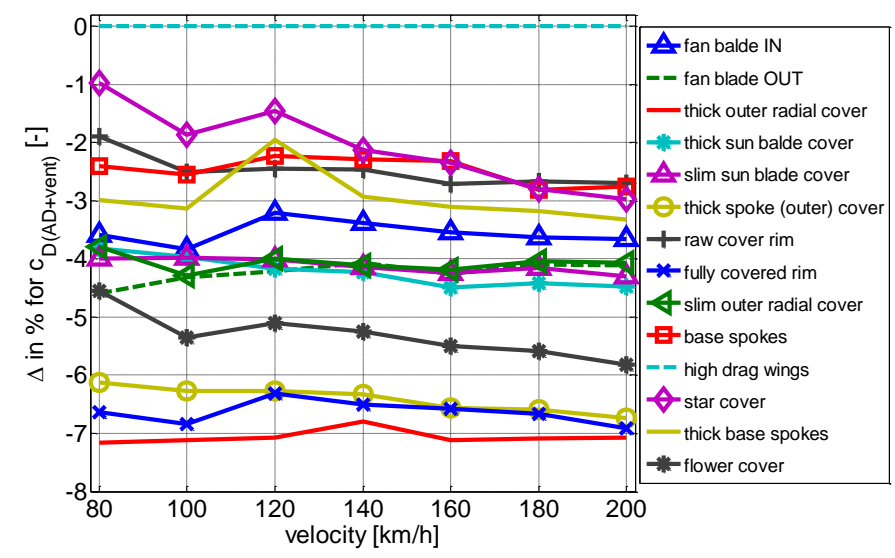

\section{Figure 13. Percentage difference in total aerodynamic resistance}

The third best design based on total aerodynamic resistance is a rim with thick spokes and outer cover. The worst configurations are the same as for the aerodynamic drag force: star cover, row rim and base spokes.

These results once again showed that ventilation resistance has a significant effect on aerodynamic performance of the vehicles and it should not be neglected.

The graph in Figure 14 shows normalized values for aerodynamic drag and ventilation resistance coefficient $\mathrm{C}_{\mathrm{D} \text { (vent) }}$ in relation to changing speed for six selected configurations.

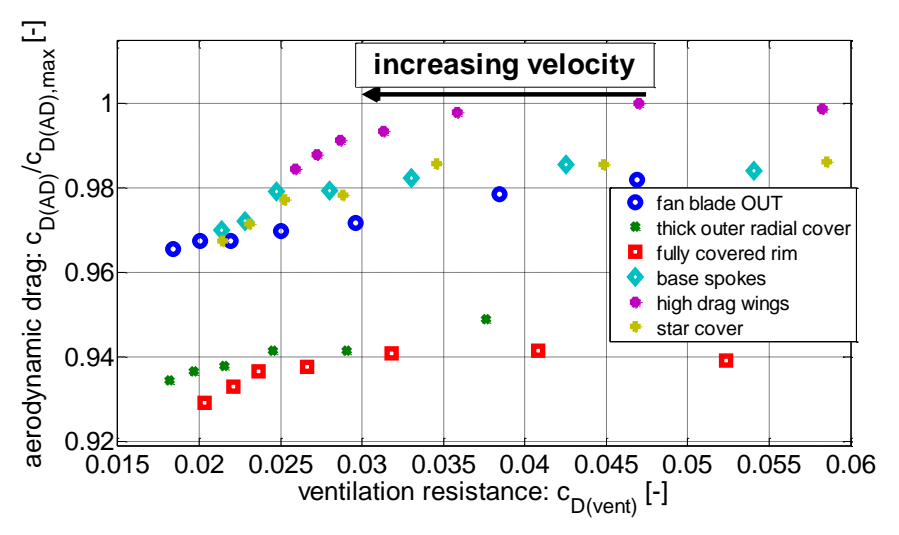

Figure 14. Aerodynamic drag vs ventilation resistance

As it can be observed ventilation resistance can be responsible for as many as 60 drag counts for slow speeds, it also can be observed that $C_{D(v e n t)}$ is much more sensitive to the velocity then $C_{D(A D)}$. That happens due to the fact that tractive force in the numerator does not increase as quickly as velocity squared in denominator, see equation 2.

Page 7 of 9
As it is favorable for optimal design to have a low drag force and a low ventilation resistance, the best designs should be found in the lower left corner of the graph. As it is expected there one can find designs with outer radius cover and fully cover rim.

As tractive forces for all four wheels have been measured, it was possible to compare ventilation resistance on front and rear wheels. An example of such comparison is given in Figure 15, where the power distributions for front and rear wheels are compared for cases of fan blades IN and OUT.

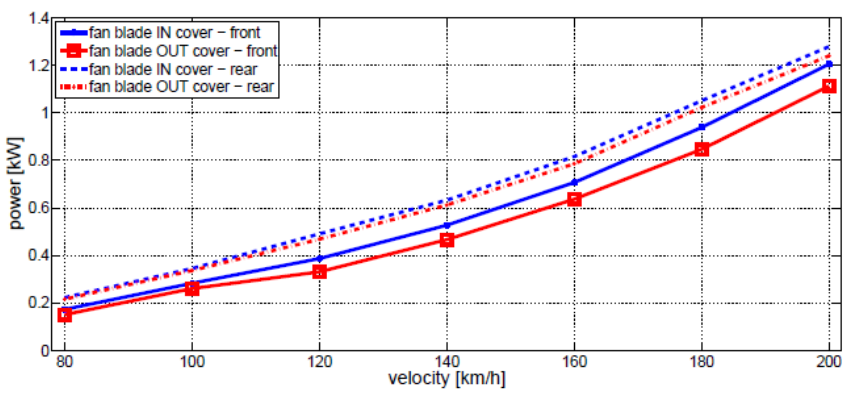

Figure 15. Power distribution for front and rear wheels

In both configurations shown ventilation resistance for front wheels is lower then for the rear. Same behavior was observed for most of other rim configurations, but not for all of them; some configurations showed absolutely opposite results.

As there was no clear trend detected further investigations are required. Since the flow field around front wheels is interdependent with the one for the rear wheels it may be of a certain interest to run tests with configurations having wheels with different rims for front and rear axles of the vehicle.

\section{CONCLUSIONS}

This investigation has shown that it was possible to measure ventilation resistance using an alternative approach to the one found in the literature. The results show that it was possible to measure similar power requirement to rotate the wheels as it was found in previous works.

Using a modular wheel system a number of 17 inch wheels with different rims were tested and the measurement data was analyzed. As expected, the ventilation resistance appeared to be independent of aerodynamic drag force as there was no direct correlation found. Considering the magnitude of ventilation resistance observed in this study, and corresponding power requirement, even between different rims of the same size, it was clear that, the presence of 
ventilation resistance should be taken into account when designing a wheel.

The rims with large outer radial cover were known to perform well in terms of aerodynamic drag force. They have been proven to be good in regards ventilation resistance as well. Moreover having a rim with thick outer radius cover was proven to be more efficient then having a fully covered wheel.

Another rim design that was found to be of a certain interest was the one with three-dimensional fan blades. It showed low ventilation resistance and it is considered to have a possibility of reducing total aerodynamic resistance if properly designed. An interesting future configuration could be to combine a radial cover with a three dimensional fan blade spoke design.

\section{REFERENCES}

[1] E. Mercker, N. Breuer, H. Berneburg and H. J. Emmelmann, "On the Aerodynamic Interference Due to the Rolling Wheels of Passenger Cars," in SAE International (Paper No: 910311), Warrendale, PA, 1991.

[2] G. Wickern, K. Zwicker and M. Pfadenhauer, "Rotating Wheels - Their Impact on Wind Tunnel Test Techniques and on Vehicle Drag Results.," in SAE International (Paper No: 970133), Warrendale, PA, 1997.

[3] W. Mayer and J. Wiedemann, "The Influence of Rotating Wheels on Total Road Load," in SAE Technical Paper 2007-01-1047, Warrendale, PA, 2007.

[4] F. Modlinger, R. Demuth and N. Adams, "New Directions in the Optimization of the Flow around Wheels and Wheel Arches," in MIRA International Conference on Vehicle Aerodynamics, Coventry, England, 2008.

[5] J. Sterneus, T. Walker and T. Bender, "Upgrade of the Volvo Cars Aerodynamic Wind Tunnel," in SAE International (Paper No: 2007-01-1043), Warrendale, PA, 2007.

[6] P. Mlinaric and S. Sebben, "Investigation of the Influence of Tyre Deflection and Tyre Contact Patch on CFD Predictions of Aerodynamic Forces on a Passenger Car," in MIRA International Conference on Vehicle Aerodynamics, Coventry, England, 2008.

[7] SKF, "Estimation of the frictional moment," [Online]. Available: SKF.com / Products / Interactive Engineering Catalogue / Rolling bearings / Principles of bearing selection and application / Friction /. [Accessed 1510 2012].

[8] Z. Qiu, C. Landström, L. Löfdahl and L. Josefsson, "Wheel Aerodynamic Developments on Passenger Cars by Module-based Prototype Rims and Stationary Rim Shields," in FISITA World Automotive Congress, Budapest, Hungary, 2010.

[9] C. Landström, L. Josefsson, T. Walker and L. Löfdahl, "An experimental investigation of wheel design parameters with respect to aerodynamic drag," in FKFS Conference, Stuttgart, Germany, 2011.

[10] C. Landström, T. Walker, L. Christoffersen and L. Löfdahl, "Influences of Different Front and Rear Wheel Designs on Aerodynamic Drag of a Sedan Type Passenger Car," in SAE International, Warrendale, PA, 2011.

\section{DEFINITIONS/ABBREVIATIONS}

$\rho=$ air density;

$\omega=$ angular velocity;

$A=$ reference area;

$C_{D}=$ drag coefficient;

$C_{D(A D)}=$ aerodynamic drag coefficient;

$C_{D(\text { vent })}=$ ventilation resistance coefficient;

$C_{D(A D+v e n t)}=$ total aerodynamic resistance coefficient;

$C F D=$ computational fluid dynamics;

$e=$ distance, by which the vertical component of the reaction force is shifted from the centerline of the wheel, when the wheel starts to rotate;

$f_{\text {inertia }}=$ distributed inertial forces due to rotation of the masses;

$f_{r r}=$ rolling resistcance coefficient;

$F_{r r}=$ rolling resistance force;

$F_{\text {trac }}=$ traction force, longitudinal component of the reaction force at the contact patch;

$F_{\text {trac }}^{\prime}=$ part of traction force that corresponds to ventilation resistance;

$M_{b e}=$ resistance moment due to friction in bearings;

$M_{b r}=$ resistance moment due to friction in brakes; 
$M_{d s}=$ resistance moment due to losses in drive shaft and gearbox;

$M_{\text {inertia }}=$ resistance moment due to inertia of the rotating parts;

$M_{s}=$ resistance moment due to the tire slip in the contact patch;

$M_{\text {vent }}=$ resistance moment cause by ventilation losses;

$N=$ vertical component of the reaction force acting on a wheel from the ground;

$S L S=$ selective laser sintering;

$T=$ torque, applied to the wheel from the drive shaft;

$V_{\infty}=\mathrm{a}$ free stream velocity;

$W D U=$ wheel drive unit. 